\title{
Effect of Exercise on Respiratory Rate among College Going Females Having Different Body Composition
}

\author{
Manas Banerjee \\ Department of Basic Science and Humanities, University of Engineering and \\ Management, Kolkata-700160,India
}

\begin{abstract}
The purposes of the study were to find out the maximum change in respiratory rate following an exercise bout and to study the recovery period of respiratory rate after completing an exercise bout in three categories of women - obese, normal and lean. Multiple group design with three independent groups was considered for the present study, age ranging between nineteen to twenty four years for the study from West Bengal. The students were further divided into three groups of 13 students according to overweight or obese group (S1), Normal group (S2) and Lean or underweight group (S3). Respiratory rate was considered as criterion of the present study and it was measured manually by observation of breath in and breathe out per minute. Standard stop watch was used for time specification. Step up and down for five minutes was used as exercise protocol. The data collected were statistically analyzed through Analysis of Variance (ANOVA) to find out the significant difference among three groups at 0.05 level of significance. Findings have revealed that respiratory rate significantly increased for all groups of subjects immediately after exercise.
\end{abstract}

\section{INTRODUCTION}

Regular physical activity and exercise improves quality of life. Any type of physical activity counts as exercise. It could be planned sport such as running, swimming, tennis or bowls, an exercise training programme, or a hobby such as cycling or walking. It could also include physical activities which are part of your daily life, such as gardening, cleaning or walking to the shops. During exercise, two of the important organs of the body come into action: the heart and the lungs. The lungs bring oxygen into the body, to provide energy, and remove carbon dioxide, the waste product created when we produce energy. The heart pumps the oxygen to the muscles that are doing the exercise.

When we exercise and our muscles work harder, our body uses more oxygen and produces more carbon dioxide. To cope with this extra demand, our breathing has to increase from about 15 times a minute (12 litres of air) when we are resting, up to about 40-60 times a minute (100 litres of air) during exercise. Our circulation also speeds up to take the oxygen to the muscles so that they can keep moving.

manas.banerjee@uem.edu.in

American Journal of Applied Mathematics and Computing 
When our lungs are healthy, we can keep a large breathing reserve. We may feel 'out of breath' after exercise, but we will not be 'short of breath'. When we have reduced lung function, we may use a large part of our breathing reserve. This may make us feel 'out of breath', which can be an unpleasant feeling, but it is not generally dangerous. It is normal to get breathless during exercise. However, regular exercise can increase the strength and function of our muscles, making them more efficient. Our muscles will require less oxygen to move and they will produce less carbon dioxide. This will immediately reduce the amount of air we need to breathe in and out for a given exercise. Training also improves our circulation and strengthens our heart.

Exercise will improve our overall physical and psychological well-being. It can decrease the risk of developing other conditions such as stroke, heart disease and depression. Regular exercise is also one of the most important interventions to prevent the onset of type-II diabetes. In order to stay healthy, we should do 30 minutes of moderate exercise five days per week. For a healthy person, moderate exercise might be walking at a pace of 4 to $6 \mathrm{~km}$ per hour. During exercise there is an increase in physical activity and muscle cells respire more than they do when the body is at rest. The heart rate increases during exercise.

The rate and depth of breathing increases this makes sure that more oxygen is absorbed into the blood, and more carbon dioxide is removed from it. The short-term effect of exercise on respiratory system is usually quite extensive and that is mainly due to the changes in the concentration of oxygen and carbon dioxide in the blood. It is due to these changes that we will notice our breathing rate go up quickly. This also makes our intercostals muscles, diaphragm, and other muscles involved in the expansion of thoracic cavity to work harder. This in turn will make it possible for us to inhale more air to deal with the increased demand for oxygen. When we exercise, our adrenal gland becomes active and prepares us for the hard work by releasing adrenaline and noradrenalin. These hormones affect the way our heart transports carbon dioxide and oxygen throughout the body. This requires our heart to beat stronger, and this is where the hormones will help by stimulating the sympathetic nervous system. Our heart rate will increase and our cardiac output will go up to help us deal with the strenuous physical activity.

Exercise leaves an effect on our diaphragm and intercostals muscles, and regular exercise will help strengthen the respiratory muscles. Over time, this also helps chest caving become larger. The respiratory volume goes up immediately, and regular exercise leads to an increase in overall efficiency of our respiratory system. In fact, people who exercise regularly develop an improved ability to consume oxygen during maximal exercise.

\section{METHODOLOGY}

Thirteen college going female students, age ranging between nineteen to twenty four years from West Bengal was selected for this study. The students were further divided into three groups according to overweight or obese group (S1), Normal group (S2) and Lean or underweight group (S3). Respiratory rate was considered as criterion of the present study. Respiratory rate was measured manually by observation of breath in and breathe out per minute, for this Step up and down for five minutes was used as exercise protocol and standard stop watch was used for time specification. 


\section{STATISTICAL PROCEDURE}

The data collected on thirteen college going female students belonging to different groups was statistically analyzed through Analysis of Variance (ANOVA) to find out the significant difference among the students at 0.05 level of significance. All calculations were done by the standard statistical procedure. Standard statistical software was used for all the calculations.

\section{FINDINGS}

\section{Table-1}

The mean value and standard deviation of respiratory rate at Rest, Immediate after exercise and the Recovery period for S-1, S-2 and S-3

\begin{tabular}{|c|c|c|c|c|c|c|}
\hline $\begin{array}{c}\text { Subje } \\
\text { ct } \\
\text { Grou }\end{array}$ & \multicolumn{2}{|c|}{ Rest } & \multicolumn{2}{|c|}{$\begin{array}{c}\text { Immediat } \\
\text { e after } \\
\text { Exercise }\end{array}$} & \multicolumn{2}{|c|}{$\begin{array}{c}\text { Recovery } \\
\text { period }\end{array}$} \\
\hline ps & $\begin{array}{c}\text { Mea } \\
\mathrm{n}\end{array}$ & SD & $\begin{array}{c}\text { Mea } \\
\mathrm{n}\end{array}$ & $\mathrm{SD}$ & $\begin{array}{c}\text { Mea } \\
\mathrm{n}\end{array}$ & SD \\
\hline S-1 & $\begin{array}{c}20.6 \\
6\end{array}$ & $\begin{array}{c}2.3 \\
0\end{array}$ & $\begin{array}{c}37.6 \\
6\end{array}$ & $\begin{array}{c}0.5 \\
7\end{array}$ & $\begin{array}{c}15.3 \\
2 \\
\min \\
\end{array}$ & $\begin{array}{c}7.0 \\
1\end{array}$ \\
\hline S-2 & $\begin{array}{c}20.1 \\
6\end{array}$ & $\begin{array}{c}2.0 \\
3\end{array}$ & $\begin{array}{c}31.0 \\
1\end{array}$ & $\begin{array}{c}3.7 \\
4\end{array}$ & $\begin{array}{c}13.3 \\
2 \\
\min \\
\end{array}$ & $\begin{array}{c}2.4 \\
1\end{array}$ \\
\hline S-3 & $\begin{array}{c}20.0 \\
1 \\
\end{array}$ & $\begin{array}{c}2.8 \\
4 \\
\end{array}$ & $\begin{array}{c}28.0 \\
1 \\
\end{array}$ & $\begin{array}{c}2.8 \\
4 \\
\end{array}$ & $\begin{array}{l}7.51 \\
\mathrm{~min}\end{array}$ & $\begin{array}{c}4.7 \\
4 \\
\end{array}$ \\
\hline $\begin{array}{c}\text { F- } \\
\text { Value }\end{array}$ & \multicolumn{2}{|c|}{0.07} & \multicolumn{2}{|c|}{$9.40^{*}$} & \multicolumn{2}{|c|}{0.31} \\
\hline
\end{tabular}

*Significant at 0.05 level (To be significant at 0.05 level the $\mathrm{F}$-value should be 4.10 )

Table-1 indicated that F-value for resting respiratory rate and the f-value for recovery period were not significant statistically but the f-value for the respiratory rate of immediate after exercise was found significant statistically.

Table-2

Results of t-test for respiratory rate at Immediate after Exercise condition for different groups

\begin{tabular}{|c|c|c|}
\hline $\begin{array}{c}\text { Groups } \\
\text { Considered }\end{array}$ & $\begin{array}{c}\text { Mean } \\
\text { Difference }\end{array}$ & $\mathbf{t}$ \\
\hline S-1 and S-2 & 6.66 & 2.03 \\
\hline S-2 and S-3 & 3.01 & 0.99 \\
\hline S-3 and S-1 & 9.68 & $2.74^{*}$ \\
\hline
\end{tabular}

Table-2 indicated that ' $t$ ' value for $\mathrm{S} 1$ - S2 and S2 - S3 were not statistically significant but ' $t$ ' value for $S 1$ - S3 was found significant statistically.

\section{DISCUSSION OF FINDINGS}

The selected respondents in this study were young and findings have revealed that respiratory rate significantly increased for all groups of subjects immediately after exercise because when we exercise our muscles work harder, our body uses more oxygen and produces more carbon dioxide. To cope with this extra demand, our breathing has to increase. The raise of respiratory rate immediate after exercise was found highest for $\mathrm{S} 1$ group and lowest for S3 group simultaneously the recovery period was found longest for $\mathrm{S} 1$ group (15.32 $\mathrm{min}$ ) and shortest for S3 group (7.51 min). 


\section{CONCLUSION}

It was concluded that there was no significant difference in recovery period of respiratory rate among female students having different body ratio, where as Result clearly indicated that respiratory rate increased significantly immediately after exercise in all categories of female students.

\section{REFERENCE}

1) Barry L. Johnson and Jack K. Nelson.(2007). Practical Measurements for Evaluation In Physical Education $3^{\text {rd }}$ ed. U.s.a.

2) Clarke, H. Harrison.(1976) Application of Measurement to Health and Physical Education, 5th Edition, New York, Prentice-Hall.

3) Galloway, R.W. (2008). Sports Training, Anatomy \& Physiological Aspects. Sports Publication, India.

4) Harold M. Barrow. (1979).A Practical Approach to Measurement in Physical Education, London, Henry Kimpton Publishers.
5) Henry E. Garrett. (2006).Statistics in Psychology and Education. New Delhi.

6) Andrea Aliverti. (2016). The respiratory muscles during exercise. Breathe, 12: 165168.

7) Burton D.A, Stokes K \& Hall G.M. (2004). Physiological effects of exercise. Continuing Education in Anaesthesia, Critical Care \& Pain, Volume 4 Number 6.

8) Steffen P.R, Austin T, DeBarros A \& Brown T. (2017). The Impact of Resonance Frequency, 25 August.

9) V.E. Hjortdal, K. Emmertsen, E. Stenbøg, T. Fründ, M. Rahbek Schmidt, O. Kromann, K. Sørensen, \& E.M. Pedersen. (2003). Effects of Exercise and Respiration on Blood Flow in Total Cavopulmonary Connection. Circulation, 108:1227-1231.

10) Svensson $H, \cdot$ Nilsson $\quad D, \cdot$ Bjermer L. \& Tufvesson E. (2012). Exhaled Breath Temperature Increases after Exercise in Asthmatics and Controls. Karger, Vol.84, No. 4. 